\title{
PAIRING OF IDENTICAL CHROMOSOMES IN AN ISOGENIC TETRAPLOID
}

\author{
R. S. CALLOW, Y. HAMEY AND S. M. PATTRICK \\ Department of Botany, The University, Manchester M13 $\mathrm{gPL}$, U.K. \\ Received 29.vii.83
}

\begin{abstract}
SUMMARY
Meiotic pairing is described for a completely homozygous tetraploid derived from successively doubled haploid barley. The high quadrivalent frequency (4.58/cell) in cells with many chiasmata is indicative, either of discrete pairing at only two independent synaptic sites per chromosome or of continuous pairing amongst many sites in close proximity. A high frequency of discordance amongst ring quadrivalents $(20.8$ per cent) leads to lagging and irregular segregation in at least 20 per cent of first meiotic divisions.
\end{abstract}

\section{INTRODUCTION}

The quadrivalent frequency of autotetraploids has long been known to be dependent on chiasma conditions (Upcott, 1939; Levan, 1940) but can also be limited at pachytene (Armstrong, 1971), even in autotetraploids newly derived from diploid inbred lines (Timmis and Rees, 1971). These observations raise the interesting possibility of differential affinity between identical products of replication and non-identical homologues: a possibility only excluded in a new polyploid of single haploid origin. Here we report on, to our knowledge, the first study of meiosis in such an isogenic tetraploid. We use the term "isogenic tetraploid" to indicate complete homozygosity and, in preference to "tetrahaploid", to avoid confusion with polyhaploids produced via anther culture (Sunderland, 1974).

\section{MATERIALS AND METHODS}

Seeds of doubled haploid Sultan barley were kindly supplied by Dr R. A. Finch (Plant Breeding Institute, Cambridge) and multiplied through two generations of selfing. After induction of tetraploidy (Jensen, 1976), the chimaeras were maintained until flowering at $20^{\circ} \mathrm{C}$ with $16 \mathrm{~h}$ days of natural light supplemented by sodium vapour lamps to a daily average of 422 to $472 \mathrm{~J} \mathrm{~cm}^{-2}$, depending on their position on the glasshouse bench. Lactopropionic orcein squashes were prepared from root-tips pre-treated for $5 \mathrm{~h}$ in 0.05 per cent colchicine, fixed in ethanol/acetic acid $(3: 1)$ and stained in Feulgen, and from ears fixed in Carnoy. At least five root-tip cells were scored per plant.

\section{Results}

Tetraploidy, representing 29 per cent of 671 mitotic cells scored, was observed in 39 of 71 plants surviving to maturity. Of twenty-nine plants examined at meiosis, only six had tetraploid anthers. 
Metaphase-I in 146 isogenic diploid pollen mother cells was extremely regular with 12 to 14 chiasmata per cell. The mean chiasma frequency of 57 tetraploid PMCs did not differ significantly from twice the value for diploid cells $(25.05$ vs. 26.93$)\left(t_{56}=0.891, P>0.30\right)$. Almost every paired arm had a single chiasma, the only exceptions being 1.2 per cent of paired arms in diploid cells which had two chiasmata. Trivalents and univalents $(0 \cdot 12 /$ cell $)$ and pairs of univalents $(0 \cdot 14 /$ cell $)$ all appear to be the products of desynapsis (table 1). In cells with at least 26 chiasmata the quadrivalent

TABLE 1

Pairing patterns

\begin{tabular}{|c|c|c|c|c|c|}
\hline \multirow{2}{*}{$\begin{array}{c}\text { Chiasmata } \\
\text { /cell }\end{array}$} & \multicolumn{4}{|c|}{ Pairing configurations/cell } & \multirow{2}{*}{$\begin{array}{l}\text { Total } \\
\text { Cells }\end{array}$} \\
\hline & I & II & III & IV & \\
\hline 21 & 0.5 & $6 \cdot 0$ & 0.5 & $3 \cdot 5$ & 2 \\
\hline 22 & $1 \cdot 5$ & 4.5 & 0.5 & $4 \cdot 0$ & 6 \\
\hline 23 & 1.8 & $5 \cdot 3$ & $0 \cdot 3$ & 3.8 & 4 \\
\hline 24 & $0 \cdot 3$ & $6 \cdot 1$ & $0 \cdot 1$ & $3 \cdot 8$ & 9 \\
\hline 25 & 0.3 & $6 \cdot 5$ & $0 \cdot 1$ & $3 \cdot 6$ & 10 \\
\hline 26 & 0.0 & 4.5 & 0.0 & 4.7 & 12 \\
\hline 27 & 0.0 & $4 \cdot 8$ & $0 \cdot 0$ & 4.6 & 8 \\
\hline 28 & 0.0 & $5 \cdot 3$ & 0.0 & $4 \cdot 3$ & 6 \\
\hline \multicolumn{6}{|l|}{ Overall } \\
\hline 25.05 & 0.40 & $5 \cdot 33$ & $0 \cdot 12$ & $4 \cdot 12$ & 57 \\
\hline
\end{tabular}

frequency does not differ significantly from a minimum pachytene expectation (Sved, 1966) of two-thirds per set of homologues (4.58 vs. 4.67$)\left(t_{25}=\right.$ $0.416, P>0.50)$ and is similar in each of the 7 sets of homologues, giving $\chi_{(2)}^{2}=0.454(P>0.70)$ for goodness of fit to the binomial $[P(I V)+P(I I)]^{7}$.

The seven trivalents observed in tetraploid cells were all in convergent orientation. Amongst 235 quadrivalents, ring formations ( 72 per cent) were at least twice as common as chains, roughly 50 per cent of each type in alternate orientation. About a fifth of ring quadrivalents was present as discordant configurations (each resembling the "diamond" in a pack of playing cards). In contrast, a single discordant (linear) example was observed amongst 67 chain quadrivalents (table 2). The occurrence of discordant

TABLE 2

Quadrivalent orientation: values in parentheses are expectations based on the $\chi^{2}$-contingency method

\begin{tabular}{ccccc}
\hline & Alternate & Adjacent & Discordant & Total \\
\hline \multirow{2}{*}{ Chain } & 31 & 35 & 1 & 67 \\
& $(33 \cdot 4)$ & $(23 \cdot 4)$ & $(10 \cdot 2)$ & \\
\multirow{2}{*}{ Ring } & 86 & 47 & 35 & 168 \\
& $(83 \cdot 6)$ & $(58 \cdot 6)$ & $(25 \cdot 8)$ & \\
\hline Total & 117 & 82 & 36 & 235 \\
\hline
\end{tabular}

$\chi_{(2)}^{2}=19.867, P<0.01$. 


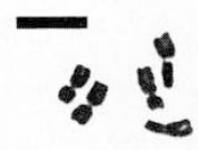

\section{"था}

กำ
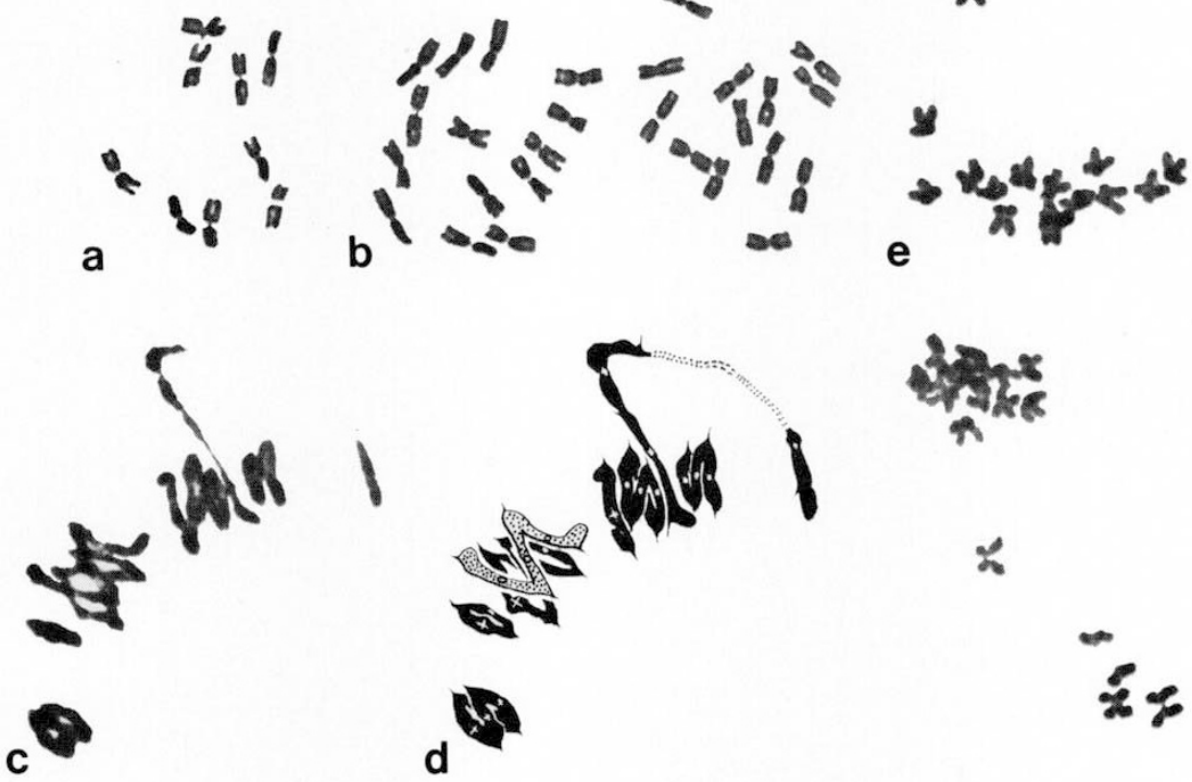

f

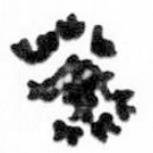

PlaTe 1. The chromosomes of isogenic Sultan barley. Mitosis: (a) $2 n=14$, (b) $2 n=28$. Meiosis in a tetraploid: (c, d) 2 bivalents, 2 chain quadrivalents and 4 alternate ring quadrivalents at metaphase-I, (e) anaphase-I 13:14 with laggard, (f) telophase-I 12:12 with two undivided laggards and two dividing. Bar equals $10 \mu \mathrm{m}$. 
quadrivalents in metaphase-I cells ( 60 per cent) was independent of the incidence of univalents (25 per cent) $\left(\chi_{(1)}^{2}=2.664, P>0.10\right)$, leaving only 35 per cent of metaphases with no obvious sources of segregational imbalance. None the less, almost two-thirds of anaphase-I divisions were at least numerically regular (table 3 ). From 0 to 2 laggards were observed in the unbalanced segregations but some of these must eventually become included in one or other daughter nucleus, since laggards are absent from 80 per cent of telophase-I divisions. Two-thirds of the persistent laggards show precocious separation (table 4) (Plate 1).

TABLE 3

Anaphase-I segregations

\begin{tabular}{ccc}
\hline Segregation & Divisions & $\%$ \\
\hline $14: 14$ & $14^{*}$ & $63 \cdot 6$ \\
$15: 13$ & 1 & - \\
$14: 1: 13$ & $5^{*}$ & $22 \cdot 7$ \\
$14: 2: 12$ & 1 & - \\
$13: 2: 13$ & 1 & - \\
\hline & 22 & \\
\hline
\end{tabular}

* Includes one cell with a side-arm bridge.

TABLE 4

Chromosome lagging at telophase-I

\begin{tabular}{|c|c|c|c|c|}
\hline $\begin{array}{l}\text { Laggards } \\
\text { Undivided }\end{array}$ & Dividing & Total & [Divisions] & {$[\%]$} \\
\hline- & - & 0 & 86 & 80.4 \\
\hline 1 & - & 1 & $1\}$ & \\
\hline- & 1 & 1 & $8\}$ & 8.4 \\
\hline 1 & 1 & 2 & $2\}$ & \\
\hline- & 2 & 2 & $3\}$ & $4 \cdot 7$ \\
\hline 1 & 2 & 3 & 2 & 1.9 \\
\hline 3 & 1 & 4 & 1) & \\
\hline 2 & 2 & 4 & $1\}$ & 2.8 \\
\hline- & 4 & 4 & 1) & \\
\hline 3 & 2 & 5 & 1) & \\
\hline- & 5 & 5 & 1) & 1.9 \\
\hline \multicolumn{5}{|l|}{ Overall } \\
\hline 0.12 & 0.32 & 0.44 & 107 & \\
\hline
\end{tabular}

\section{Discussion}

Metaphase quadrivalents in tetraploids result from changes in zygotene pairing partner flanked by sufficient chiasmata at pachytene (Darlington, 1965). Within the nuclear complement of an autotetraploid, they are usually most frequent amongst the largest chromosomes, since the incidences of both synaptic exchange and chiasmata often increase with chromosome length (John and Henderson, 1962). Quadrivalent frequency in newly synthesised autotetraploids is also subject to effects of genotypic variation in 
the original diploid population. These effects can be produced via changes either in chiasma frequency (Hazarika and Rees, 1967) or in zygotene pairing (Roseweir and Rees, 1962). Synaptic variation in a new population of autotetraploids implies at least occasional differential affinity between identical products of replication and non-identical homologous chromosomes. Such extreme sensitivity has been observed directly in Giemsa C-banded autotetraploid cells of the grasshopper Euchorthippus pulvinatus gallicus (Giraldez and Santos, 1981).

Synapsis in an isogenic tetraploid will be free of differential affinity assuming that no recent mutation has occurred to distinguish otherwise identical homologues. Here, the metaphase quadrivalent frequency of cells with many chiasmata will be dependent simply on the mechanics of the pairing process. If choice of pairing partner is restricted to a single autonomous synaptic site on each chromosome, then no change of partner is possible. Two independent sites on each chromosome will produce a pachytene quadrivalent twice as often as two bivalents, if pairing is random (Sved, 1966). More than two sites will give a higher quadrivalent frequency (Jackson and Casey, 1982). Very large numbers of synaptic sites are, however, likely to be in such close proximity to each other thay they will not behave independently. Under these conditions, the quadrivalent frequency would not be expected to rise with increasing numbers of synaptic sites and observations of higher polyploids would be needed before any inference could be made as to whether pairing is discrete or quasi-continuous (Callow and Gladwell, 1980).

In high chiasma frequency cells of isogenic tetraploid Sultan barley, quadrivalents are more frequent than pairs of bivalents and equally common in each of the seven sets of identical homologues. Their frequency is in line with the minimum random expectation and greater than has been observed in many presumably heterozygous autotetraploids (Morrison and Rajhathy, $1960 a, b)$. It even exceeds that of high chiasma frequency cells in autotetraploids newly derived from inbred lines of rye (Timmis and Rees, 1971). Interestingly, a quadrivalent frequency of two-thirds has been recorded for autotetraploid Hordeum bulbosum (Berg, 1936; Davies, 1958). Indeed, quadrivalent frequencies in excess of two-thirds $(4.9$ to $5 \cdot 1 /$ cell) have been reported for some varieties of autotetraploid $H$. vulgare but these frequencies were obtained from material in which the configurations of the quadrivalents were apparently difficult to determine and inconsistent with genic evidence of preferential pairing in the same tetraploid varieties (Reinbergs et al., 1970).

Evidently the high quadrivalent frequency of the isogenic tetraploid must result from random association of identical chromosomes. It is consistent either with a model based on pairing at only two independent synaptic sites per chromosome or with a model where pairing is more or less continuous. Although these two possibilities need to be distinguished using higher ploidy levels, recent biochemical evidence (Hotta and Stern, 1981) supports the intuitive view (John, 1976) that pairing specificity is unlikely to be restricted to a small number of autonomous synaptic sites.

Discordant orientation of quadrivalents appears to be an important source of irregular chromosome segregation in the isogenic tetraploid. This may explain the low floret fertilities recorded for normal autotetraploid varieties of barley, especially as the proportion of regular anaphase-I segregations is very similar in both cases (c. 63 per cent) (Reinbergs et al., 1970). 


\section{REFERENCES}

ARMSTRONG, K. C. 1971. Chromosome associations at pachytene and metaphase in Medicago sativa. Can. J. Genet. Cytol., 13, 697-702.

BERG, K. H. VON, 1936. Autotetraploidie bei Hordeum bulbosum. Der Züchter, 8, 151-158.

CAllow, R. S. AND GLADWELl, 1. 1980. Chromosome synapsis in hexaploids. $J$. theor. Biol., $87,703-722$.

DARlington, C. D. 1965. Cytology. Churchill, London.

DAVIES, D. R. 1958. Male parthenogenesis in barley. Heredity, 12, 493-498.

GIRALDEZ, R. AND SANTOS, J. L. 1981. Cytological evidence for preference of identical over homologous but not identical meiotic pairing. Chromosoma, 82, 447-451.

HAZARIKA, M. H. AND REES, H. 1967. Genotypic control of chromosome behaviour in rye. $X$. Chromosome pairing and fertility in autotetraploids. Heredity, 22, 317-332.

HOTTA, Y. AND STERN, H. 1981. Small nuclear RNA molecules that regulate nuclease accessibility in specific chromatin regions of meiotic cells. Cell, 27, 309-319.

JACKSON, R. C. AND CASEY, J. 1982. Cytogenetic analyses of autotetraploids: models and methods for triploids to octoploids. Amer. J. Bot., 69, 487-501.

JENSEN, C. J. 1976. Barley monoploids and doubled monoploids: techniques and experience. Barley Genetics III, München, 316-345.

JоHN, B. 1976. Myths and mechanisms of meiosis. Chromosoma, 54, 295-325.

JOHN, B. AND HENDERSON, S. A. 1962. Asynapsis and polyploidy in Schistocerca paranensis. Chromosoma, 13, 111-147.

LEVAN, A. 1940. Meiosis in Allium porrum, a tetraploid species with chiasma localization. Hereditas, 26, 454-462.

MORRISON, J. W. AND RAJHATHY, T, 1960a. Frequency of quadrivalents in autotetraploid plants. Nature, 187, 529-530.

MORRISON, J. W. AND RAJHATHY, T. $1960 \mathrm{~b}$. Chromosome behaviour in autotetraploid cereals and grasses. Chromosoma, 11, 297-309.

REINBERGS, E., KAO, K. N., HARVEY, B. L. AND SHEBESKI, L. H. 1970. Meiotic behavior and preferential pairing in autotetraploid barley. Crop Sci., 10, 569-571.

ROSEWEIR, J. AND REES, H. 1962. Fertility and chromosome pairing in autotetraploid rye. Nature, 195, 203-204.

SUNDERLAND, N. 1974. Anther culture as a means of haploid production. In Kasha, K. J. (ed.) Haploids in Higher Plants: Advances and Potentials, University of Guelph, pp. 91-122.

SVED, J. A. 1966. Telomere attachment of chromosomes, some genetical and cytological consequences. Genetics, 53, 747-756.

TIMMIS, J. N. AND REES, H. 1971. A pairing restriction at pachytene upon multivalent formation in autotetraploids. Heredity, 26, 269-275.

UPCOTT, M. B. 1939. The genetic structure of Tulipa. III. Meiosis in polyploids. J. Genetics, 37, 303-339. 